\title{
O POEMA: FONTE DE INSPIRAÇÃO PARA A PRODUÇÃO TEXTUAL
}

\author{
Aira Suzana Ribeiro Martins (Colégio Pedro II/ SELEPROT)
}

Resumo: Como sabemos, um dos objetivos do ensino da escola é levar o aluno ao domínio da língua padrão em situações concretas de interação. É necessário, do mesmo modo, que o indivíduo tenha percepção clara das diferenças entre as formas de expressão, de acordo com as situações em que se encontre. A grande dificuldade do professor é motivar o aluno para a produção de um texto. Nesse sentido, acreditamos que a criação de situações que levem o aluno ao sentimento de prazer pela leitura e produção de um poema seja um elemento facilitador inicial para o sucesso das aulas de produção textual. Nosso trabalho pretende fazer o relato de atividades de leitura e produção do gênero poético, com vistas ao prazer estético e motivação para a criação de textos.

Palavras-chave: Leitura; Produção textual; Poesia; Prazer estético.

Abstract: As we know, one of the goals of school education is to make students master their standard language in real-life interaction situations. Accordingly, an individual needs to have a clear understanding on the differences between forms of expression, according to the situations in which they find themselves. The great challenge for teachers is to motivate a student to produce a text. In this regard, we believe that creating situations that lead students to a feeling of pleasure when reading and producing a poem is an initial facilitating element for success in textual production classes. Our work aims to provide a report on activities of poetry reading and production, focused on an aesthetic pleasure and motivation for text creation.

Keywords: Reading; Textual production; Poetry; Aesthetic pleasure.

\section{INTRODUÇÃO}

Neste trabalho, defendemos a ideia de se iniciarem as atividades de leitura e produção textual a partir do gênero poético. Nossa experiência em sala de aula mostra que 
o trabalho com o poema proporciona ao aluno o prazer estético. Isso vai facilitar as atividades de elaboração de textos na modalidade escrita da língua.

Observamos que, usualmente, o poema é um gênero pouco visto em sala de aula. Nos livros didáticos, o poema aparece, geralmente, como leitura complementar, algo para entreter o aluno, não para ser comentado, analisado ou admirado. A leitura desse texto vai depender da sensibilidade do professor em chamar atenção para a beleza ou originalidade do poema.

Um dos objetivos do ensino da língua é levar o aluno ao domínio do registro culto em situações concretas de interação. A escola deve também capacitá-lo para a produção de enunciados, com a percepção clara das diferenças entre as formas de expressão adequadas para cada contexto. É necessário, do mesmo modo, que o aprendiz seja capaz de, ao concluir o Ensino Médio, identificar os diferentes gêneros textuais, bem como produzir um texto na modalidade escrita ou oral da língua, de acordo com as necessidades comunicativas nas quais se encontrar.

De acordo com Azeredo (2007), uma política de ensino da língua só será efetivamente democrática e inclusiva se for capaz de habilitar os estudantes para buscar e adquirir 
conhecimento por conta própria, em toda a variedade de fontes, principalmente as escritas. Eles devem ter condições de se expressar com clareza e desenvoltura nas duas modalidades da língua - oral e escrita - as informações, os conhecimentos e as ideias que queiram comunicar a outras pessoas.

A conquista de todas essas habilidades, entretanto, é resultado de um longo processo de escolarização pelo qual o indivíduo passa na instituição escolar. Para que o estudante chegue ao final do Ensino Médio expressando-se oralmente ou por escrito de forma satisfatória, é importante que a escola faça um trabalho interdisciplinar para o ensino da leitura e da expressão oral e escrita.

Neste texto, queremos mostrar a importância da atividade de leitura e de expressão escrita. Acreditamos que uma prática efetiva com o texto literário e com variadas expressões artísticas possa auxiliar o indivíduo a, não só ser capaz de adquirir conhecimentos de forma independente, como também ler e apreciar um texto literário. Uma prática de leitura constante, na qual o estudante tenha contato com textos literários de autores consagrados e outras linguagens vai desenvolver sua sensibilidade para o belo, torná-lo receptivo às atividades inovadoras, além de contribuir para a formação de seu conhecimento enciclopédico. 
A riqueza de atividades vai levar o indivíduo também a uma competência interpretativa. A aquisição dessa habilidade muito vai auxiliá-lo a se tornar um indivíduo consciente e crítico dos acontecimentos da sociedade à qual pertence.

Há um pouco de dificuldade por parte da escola de fazer um trabalho interdisciplinar por diversos motivos, como a resistência de muitos professores ou a escassez de tempo em cumprir o conteúdo programático. O excesso de atividade docente faz também com que o livro didático seja o recurso mais utilizado pelo mestre.

O aproveitamento de variadas linguagens nos momentos dedicados à leitura em silêncio ou em voz alta vai tornar mais prazeroso o ato de ler. Essa riqueza de experiências também possibilita a formação de uma cultura enciclopédica e, consequentemente, a ampliação do repertório do indivíduo, além de uma socialização mais efetiva.

\section{A ORALIDADE EM SALA DE AULA}

Não podemos negar, na história da humanidade, a importância das tradições orais. Como lembra Zumthor (2010), civilizações arcaicas e muitas culturas modernas se mantêm pela oralidade.

Antes do aparecimento da escrita, o acervo cultural dos povos era elaborado em versos ritmados. Os hinos religiosos 
dedicados a alguma divindade, canções festivas, cantigas para dançar, acalantos e marchas militares envolviam música instrumental, dança e recitação. Essas obras, cuja memorização era imposta aos jovens por ocasião de sua iniciação na sociedade oral, se apresentavam sob a forma de poesia, de acordo com Havelock (1996).

A elaboração de textos de forma metrificada, com a disposição de palavras fixadas pelo ritmo, foi encontrada para que não se perdessem. O ritmo da dança, dos instrumentos musicais e da melodia representavam recursos que funcionavam como auxiliares no processo de memorização dos textos.

Originalmente orais, narrados em versos. O cordel, gênero tão apreciado no Brasil, origina-se desse hábito de contar histórias oralmente. Assim como as epopeias antigas, o cordel pode ser apresentado por indivíduos iletrados. Até hoje, os cantadores de cordel têm o auxílio das rimas para facilitar a memorização.

A voz, como observa Zumthor (2010), se encontra simbolicamente presente na A instituição religiosa, por sua vez, deposita na palavra falada todo o simbolismo sagrado, como a tradição cristã, que considera Cristo o Verbo. As culturas africanas chegam a atribuir valores às características 
da voz, como timbre e altura. Austin (1965), com a criação da teoria dos atos de fala, defende a ideia de que dizer, além de transmitir informações, é também uma forma de agir sobre o interlocutor e sobre o mundo circundante, ou seja, de acordo com essa teoria, dizer é realizar ações. Enunciados como: "Eu te batizo", "Eu te condeno à prisão", "Eu confiro a você o grau de Mestre ou Doutor.", servem para executar atos de batizar, condenar, conceder uma titulação, entre outros.

Como vemos, a palavra falada era e ainda é o principal elemento de comunicação nas sociedades ágrafas e continua tendo um papel privilegiado no mundo letrado.

Em relação ainda à oralidade, a poesia, sobretudo oral, é um fenômeno comum a todos. Todas as culturas têm seu repertório de canções, quadras, trava-línguas e parlendas. O hábito de contar histórias faz parte da natureza humana. Nossa vida é impregnada de poesia oral, já que estamos cercados de canções dos mais variados gêneros.

Como podemos ver, a palavra falada nunca perde sua importância, a despeito do aparecimento das mais variadas tecnologias, envolvendo ou não a oralidade. A escola não pode ignorar o papel da oralidade nas situações do dia a dia e, consequentemente, a necessidade da criação de situações com ênfase na expressão oral visando à proficiência do indivíduo nas situações envolvendo a língua falada. 
Desse modo, concordamos com Ramos (1997), que defende a ideia de que a palavra falada deva ser o ponto de partida para se chegar o produto final, que é a produção do texto escrito.

Em relação a esse fato, Castilho (1990) lembra que muitos processos de constituição da língua se encontram na modalidade oral. São comuns, na fala, as hesitações, as reestruturações em diversos níveis, como lexical, sintático, semântico e discursivo. Logo, é importante, para a compreensão da arquitetura do texto escrito, a conscientização de que a escrita é resultado de um processo semelhante ao que se observa na fala.

Ramos (1997) observa que as diferenças dialetais na fala se mostram mais naturais. Ela chama atenção ainda para o fato de que é possível refletir sobre a língua a partir das ocorrências observadas na oralidade.

De que forma a escola pode fazer o trabalho de reflexão sobre a língua numa atividade de leitura, da maneira mais agradável possível? Como sabemos, há diversos autores de nossa literatura que empregam uma linguagem mais coloquial em suas criações. Isso vai fazer com que o aluno compreenda que os diversos modos de falar são igualmente ricos de recursos expressivos e pertinentes 
aos diferentes usos. A atividade de contação de histórias produz interessantes resultados. Ao pedir que o aluno leia uma história e a reconte para uma plateia, que pode ser formada pelos próprios colegas de turma, percebe que não é possível repetir o texto exatamente como o autor a criou. Nos momentos em que lhe fogem as palavras do texto original, é necessário improvisar. Esse tipo de atividade é bastante interessante, pois alguns alunos preferem recontar a narrativa utilizando um léxico mais próximo de seu registro. Há poemas de autores consagrados como Manuel Bandeira, Vinicius de Moraes, Manuel de Barros, José Paulo Paes, Ferreira Gullar, entre outros, que se apresentam num registro bem coloquial. Textos poéticos de autores contemporâneos como Sérgio Cappareli e Eucanaã Ferraz também são muito bem recebidos pelo leitor mais jovem.

Para finalizar esta parte de nosso texto, as palavras de Cecília Meireles (1970, p.492) bem sintetizam tudo o que foi discutido nas linhas anteriores:

Ai, palavras, ai palavras, Que estranha potência a vossa!

$\mathrm{Ai}$, palavras, ai palavras, Sois o vento, ides ao vento, E, em tão rápida existência, Tudo se forma e transforma.

(...) 


\section{A LEITURA E PRODUÇÃO DO POEMA}

Sendo a palavra o principal instrumento de expressão, no processo de leitura e produção textual, ela deve ser posta em destaque na atividade de leitura. Conforme observamos anteriormente, cremos que o gênero mais propício para tal trabalho seja o poema, pelo fato de ser possível perceber a importância da seleção lexical, em virtude do tema escolhido e dos efeitos sonoros pretendidos, como rimas, assonâncias e aliterações.

Como afirma Cecília Meireles, a palavra é poderosa. Acreditando nesse poder, numa proposta de leitura e produção textual é importante que o aluno se sinta envolvido pela força mágica da palavra, facilmente observada no poema. Finalizada a leitura, ele deve estar motivado ao trabalho com a palavra.

Embora saibamos que a elaboração de um poema seja uma tarefa de grande complexidade, observamos que esse trabalho de elaboração de texto do gênero poesia, desde que antecedido com leituras motivadoras, traz grande prazer ao aluno. Para o jovem escritor, essa atividade soa como um jogo com as palavras.

Com base nessa ideia, realizamos projeto de leitura e produção textual de poemas com turmas de sexto ano do Ensino Fundamental. 
Consideramos também o fato de haver inúmeros poemas elaborados em um registro mais coloquial, que são bem recebidos pelo leitor mais inexperiente, para a execução de nossa proposta.

Como observa Negreiros (2014), a leitura do texto poético pode ser uma interessante estratégia de despertar a atenção do aluno para o texto literário. De acordo com o estudioso, alguns recursos linguísticos orais, empregados na fala cotidiana podem ser encontrados em inúmeros poemas de autores mais modernos e até mesmo os mais consagrados. Podemos ver marcas de oralidade em poemas dos autores já citados anteriormente, como Manuel Bandeira, Carlos Drummond de Andrade, Ferreira Gullar, Sérgio Capparelli e Eucanaã Ferraz, entre outros.

Negreiros (2014) chama atenção para o fato de que há obras que apresentam claramente aspectos da sintaxe oral, como repetições, paráfrases, cortes e correções.

Vejamos este exemplo típico de sintaxe do registro coloquial:

PORQUINHO-DA-ÍNDIA

Quando eu tinha seis anos

Ganhei um porquinho-da-índia.

Que dor no coração me dava

Porque o bichinho só queria estar

debaixo do fogão!

Levava ele pra sala 
Pra os lugares mais bonitos mais limpinhos

(...)

(Libertinagem, BANDEIRA, p.208)

Como vemos, o poema de Manuel Bandeira é rico de ocorrências típicas da oralidade, como, no nível fonológico, a preposição "pra", em que o fenômeno da epêntese suprimiu uma vogal da palavra. Outra ocorrência na dimensão sintática, típica da linguagem coloquial, mais encontrada na fala, é o complemento verbal representado por um pronome pessoal do caso reto.

O próximo excerto, ainda de Manuel Bandeira, mostra um exemplo do registro não padrão da língua:

QUINTA BACHIANA

Irerê, meu passarinho

Do sertão do Cariri, Irerê, meu companheiro,

Cadê viola?

Cadê meu bem?

Cadê Maria?

Ai triste sorte do violeiro cantado!

Sem a viola em que cantava o seu amô,

(...) (Mafuá do Malungo, p.412-413)

Como podemos perceber, a obra de Manuel Bandeira é rica de passagens típicas da "língua do povo", como o próprio poeta denomina. Esse poema, que é a letra de uma melodia composta por Villa Lobos, mostra outro exemplo de mudanças fonológicas muito encontradas no 
registro não padrão da língua, como o desaparecimento do fonema consonantal fricativo velar sonoro $/ \gamma /$, fenômeno denominado apócope. "Nesse trecho do poema também encontramos o termo cadê, que é uma forma popular da expressão adverbial que é de ou onde está", de acordo com o Dicionário Houaiss (2010, p.556).

Para os leitores mais jovens, temos um exemplo de Eucanaã Ferraz (2009, p.33) no qual se encontra o uso de registro bem familiar:

CURUPIRA

Uri!Uri! Uuuu!liiiiii...

Ouve só! O que foi isso?

Olha lá! Que é? Cotia? Hum-hum...

Caçador viu pegada, foi atrás.

Corre-corre, não demorou muito,

Caçador deu de cara com o Curupira!

Cruzes!

Ele mesmo, o Curupira curumim

Guardião das matas, bole com ele pra ver!

O cabelo verde, comprido...

Quando o caçador pôs reparo

Nos pés do guri, viradas pra trás,

Caçador se mijou de medo!

Ai que Curupira ficou se rindo

Aquele seu riso branco, riso comprido...

Uri! Uri! Uuuu!liiiiii...

Como vemos, o autor, com a utilização de uma linguagem num registro bem coloquial, procura interagir com o leitor. Por meio da função fática da linguagem, cujo 
objetivo é estabelecer, prolongar ou interromper uma comunicação. Vemos, no poema, os seguintes versos: "Uri! Uri! Uuuu!liiiiii.../Ouve só! O que foi isso?/Olha lá! Que é? Cotia? Hum-hum...". Além dos verbos no imperativo, versos interrogativos, as onomatopeias, comuns da oralidade, passam para o leitor o efeito realidade, convidando o leitor a participar dos acontecimentos. O emprego do marcador conversacional "aí", da preposição "pra", da expressão regional "bole" e da forma verbal "mijou", contribuem para certa queda de expectativa do leitor em relação ao fato de acreditar que o texto poético seja elaborado em uma linguagem rebuscada.

Vejamos este exemplo de Manuel de Barros:

DE MENINOS E DE PÁSSAROS Poeminhas pescados

Numa fala de João

I

O menino caiu dentro do rio, tibum, ficou molhado de peixe... a água dava rasinha de meu pé. II

João foi na casa do peixe remou a canoa depois, pan, caiu lá embaixo na água. Afundou.

Tinha dois pato grande. Jacaré comeu minha boca do lado de fora. (...) (1961, p.13) 
Podemos ver que o autor emprega um registro também coloquial, com usos típicos da linguagem infantil, como as onomatopeias, a sintaxe própria da fala simples do povo e um léxico próprio de crianças.

Exemplos citados anteriormente representam uma mostra de interessantes obras poéticas, cujos autores procuram criar uma situação de oralidade, em que o eu lírico se dirige para um suposto interlocutor. Como vemos, os autores procuram criar efeitos de sentido próximos da modalidade oral da língua. Cremos que textos que deem ilusão de uma situação cotidiana podem auxiliar o professor a desmitificar a ideia de que o texto literário, sobretudo o poético, seja impossível de ser lido ou produzido.

Acreditamos que, desse modo, o leitor menos experiente, ao encontrar um léxico e construções sintáticas próximas de seu registro, com expressões da fala coloquial, emprego de rimas e temas cotidianos não terá dificuldades em encontrar pontos comuns com sua bagagem de conhecimentos.

\section{A PRODUÇÃO TEXTUAL}

Conforme observa Marcuschi (2008) o texto é um processo e não pode ser considerado um produto acabado. Desse modo, é considerado um evento comunicativo sempre emergente de novos sentidos. 
De acordo com a teoria semiótica de Peirce (1975), esses novos sentidos seriam o processo de semiose, que faz com que um signo, no caso, o sentido do texto poético, se desenvolva em outro(s) signo(s), apontando novas possibilidades de leitura. Essa experiência é única, pois os signos que se desenvolvem a cada leitura estarão relacionados às experiências do sujeito leitor. Por isso, o momento de leitura de um texto deve ser acompanhado de outras leituras, com outras linguagens, de outras matrizes da linguagem e do pensamento, como a imagem ou a melodia.

Uma experiência agradável com um texto no gênero poético pode ter outros desdobramentos que enriquecerão a experiência, como a leitura oral cuidadosa, com respeito à entonação, uma representação por meio de imagens ou mesmo a elaboração de um poema.

Acreditamos que o instante de desenvolvimento dos signos na mente leitora, a partir de uma leitura rica e vivenciada, seja oportuno à proposta de produção de um texto. O tema pode ser o mesmo do texto lido. $\mathrm{O}$ aluno, desse modo, poderá passar para o papel o signo desenvolvido na leitura que fez do texto apresentado pelo professor.

Como já afirmamos, as primeiras atividades de leitura e produção textual podem ser no gênero poema. 
Acreditamos que a brincadeira com sons e ritmos faça parte da natureza do homem. Desse modo, os momentos posteriores à leitura são propícios à elaboração de um poema, pois esse gênero está bem próximo da vivência dos mais jovens.

O tema deste texto surgiu de resultados de atividades de leitura e produção textual desenvolvidas em sala de aula. Percebemos que o trabalho com poemas no início do ano letivo facilita o trabalho de produção textual. Após essa experiência prazerosa, o estudante se sente mais seguro e incentivado a produzir outros textos em outros gêneros.

Podemos relatar uma atividade de leitura realizada em dois tempos de aula, que teve como resultado a criação de belíssimos poemas produzidos por alunos de uma turma de sexto ano do Ensino fundamental.

Inicialmente fez-se a leitura de poemas de vários autores sobre os quatro elementos da natureza. Após a atividade de leitura, propôs-se que cada um selecionasse o elemento da natureza com o qual se identificasse mais: a água, a terra, o fogo ou o ar. Escolhido o elemento, cada um expôs sua escolha e a justificativa. Após a apresentação de cada um, sugerimos a elaboração de um poema em que o eu lírico fosse o elemento escolhido. 
Apresentamos um poema:

O VENTO

Cá estou

Em todo canto

Levando a vida

A assobiar.

Voo, voo

E minha casa

É no ar.

Posso ser quente,

Frio, forte ou fraco.

Meu dilema é bagunçar

Folhas, livros, tudo

Tudo muda de lugar.

Autor: Nicolas Rodrigues. Turma 602.

Como vemos, o aluno, numa linguagem bem coloquial, próxima de seu registro de língua, criou um texto em versos, divertido e com muita criatividade. Após a elaboração do poema, cada um ilustrou seu texto, apresentou-o num sarau, sendo ouvido com muito interesse e receptividade. Após a apresentação, os trabalhos foram afixados num mural dividido em quatro partes: uma parte para os poemas sobre a terra, outra para os textos sobre ar, a terceira parte foi dedicada à água e a última parte recebeu poemas sobre o fogo.

\section{CONSIDERAÇÕES FINAIS}

Como sabemos, a falta de capacidade leitora e de habilidade de escrita são os grandes problemas encontrados em nossos discentes. A Organização para a 
Cooperação e o Desenvolvimento Econômico, que avaliou a situação escolar de 64 países, divulgou relatório com a informação de que o Brasil é um dos dez com mais alunos com baixo rendimento em Leitura, Matemática e Ciências. De acordo com o documento, 1,1 milhão de estudantes brasileiros com 15 anos não têm capacidades elementares para compreender o que leem nem capacidades essenciais de Matemática e Ciências.

Sabemos que a raiz do problema está na dificuldade de leitura, pois é impossível resolver um problema de Matemática ou Ciências sem a capacidade de interpretação. Desse modo, é urgente que a escola tenha mais empenho no trabalho com a leitura e a produção textual, pois a capacidade de escrever um texto coeso e coerente é adquirida a partir da leitura feita com frequência.

A teoria semiótica muito auxilia no trabalho de leitura e escrita com o aluno. A leitura de textos em variados gêneros e o contato com múltiplas linguagens vão contribuir para que a mente interpretadora seja rica de experiências. Acreditamos que o momento mais adequado para a proposta de uma produção textual seja após uma leitura rica e significativa para o aluno. Enquanto se processa a semiose, o indivíduo terá mais oportunidade de passar para o papel textos criativos e repletos de informatividade. 
Como comentamos anteriormente, defendemos a ideia de que a elaboração de um poema deva ser a primeira atividade de produção textual do ano letivo. O sucesso alcançado com a criação de um texto em versos, exposto em um mural, pode facilitar o trabalho do professor em relação à resistência do aluno em elaborar um texto. É importante também que a produção de textos tenha sempre uma finalidade, como uma apresentação para os colegas, um cartão ou um convite para um amigo, um bilhete para o professor, uma carta para a direção da escola, para a administração regional do bairro ou até mesmo para um jornal. A divulgação do texto vai fazer com que o autor se empenhe em produzir um texto de qualidade.

Como vimos, o trabalho com a leitura e com a escrita pode ser realizado em qualquer contexto escolar, até mesmo em escolas com poucos recursos tecnológicos. As experiências de leitura e escrita irão, cada vez mais, preparar o aluno não só para as atividades escolares como também para os desafios de sua vida como cidadão.

\section{REFERÊNCIAS}

AUSTIN, John Langshaw (1965). How to do things with words: The William James Lectures delivered at Harvard University. Oxford: Clarendon Press. AZEREDO, José Carlos (2007). Ensino de Português. Fundamentos, percursos, objetos. Rio de Janeiro: Zahar.

BANDEIRA, Manuel (1975). Obra completa. Rio de Janeiro: Editora Nova Aguilar. 
BARROS, Manuel (1961). Compêndio para uso dos pássaros. Rio de Janeiro: Livraria São José.

CASTILHO, Ataliba (1990). Português falado no ensino da gramática. São Paulo: Letras de Hoje.

FERRAZ, Eucanaã (2009). Bicho de sete cabeças e outros seres fantásticos. São Paulo: Companhia das Letrinhas.

HAVELOCK, Eric A. (1996). A revolução da escrita na Grécia Antiga e suas consequências. São Paulo: Editora da Universidade Estadual Paulista.

HOUAISS, Antônio (2010). Grande dicionário Houaiss da Língua Portuguesa. Rio de Janeiro: Editora Objetiva.

MARCUSCHI, Luiz Antônio (2008). Produção textual, análise de gêneros e compreensão. São Paulo: Parábola Editorial.

MEIRELES, Cecília (1970). "O romanceiro da Inconfidência". In:

Obra completa. Rio de Janeiro: Editora Nova Aguilar.

NEGREIROS, Gil (2014). “Oralidade e poesia em sala de aula”. In: ELIAS, Vanda Maria (Org.) Ensino de língua portuguesa. Oralidade, escrita, leitura. São Paulo: Editora Contexto.

PEIRCE, Charles Sanders (1975). Semiótica. São Paulo: Editora Perspectiva. RAMOS, Jânia M. (1997). O espaço da oralidade em sala de aula. São Paulo: Editora Martins Fontes.

ZUMTHOR, Paul (2010). Introdução à poesia oral. Belo Horizonte: Editora UFMG.

Aira Suzana Ribeiro Martins possui Graduação em Letras pela Universidade Federal do Rio de Janeiro (1977), Mestrado em Letras pela Universidade do Estado do Rio de Janeiro (1999) e Doutorado em Letras pela Universidade do Estado do Rio de Janeiro (2006), atuando principalmente nos seguintes temas: Estilística, Semiótica, Léxico, Ensino e Dialetação. É membro do Grupo SELEPROT de pesquisas na área de Semiótica, Leitura e Produção de Textos, coordenado pela Professora Doutora Darcilia Simões. Faz parte também do Grupo LITESCOLA de pesquisas na área de Literatura e outras linguagens na Escola Básica, 
coordenado pela Professora Doutora Ana Cristina Viegas. Leciona no Ensino Fundamental e no Programa de Mestrado Profissional em Práticas de Educação Básica do Colégio Pedro II. É também supervisora do Programa de Residência Docente do mesmo colégio.

Recebido em 02 de junho de 2016. Aprovado em 29 de junho de 2016. 